\title{
The Bright side isn't that bright: HIV treatment optimism as a case of optimistic bias
}

\author{
Gidi Rubinstein* \\ School of Behavioral Sciences, Netanya Academic College, Netanya, Israel
}

\begin{abstract}
The term "optimism bias" describes the inclination of individuals to believe they are at lower risk than others to experience a negative event. The presentstudy applies this concept to HIV treatment optimism (HTO) by comparing the risk of contracting HIV, as perceived by gay laymen, to realistic evaluations of HIV specialists. After receiving responses from both professionals and laymen regarding HIV in the era of highly active antiretroviral therapy (HAART), a new HTO scale was developed. 301 members (mean age = 33) of the largest Israeli gay dating website filled in Costa and McCrae's (1992) NEO-FFI, Zuckerman's (2002) Impulsive Sensation Seeking (ImpSS), Gimley, Prochaska, and Prochaska's (1993) Condom Use Assertiveness (CUA), and the HOT scales. Multiple regression analyses revealed negative effects of CUA, education, and conscientiousness and positive effects of age and acceptance of sexual orientation on HTO. HIV patients were found to be more optimistic than non-patients. Theoretical, as well as medical education applications, are discussed.
\end{abstract}

Optimism bias causes individuals to believe they are less at risk than others to experiencing a negative event [1]. This can be seen in a number of situations. The best example in the context of this study would be Men who have Sex with Men (MSM), who practice unprotected anal sex and believe they are not likely to be infected by HIV. Although optimism bias occurs for both positive and negative events, there is more evidence suggesting that it is stronger for negative events [2]. People who believe they have more control over events tend to be optimistically biased. Thus, men who believe they have control over being infected with HIV are more likely to evaluate their risk of contracting the disease as low [3]. When asked to rate the risks of their behavior for contracting AIDS, only few gay men engaging in highrisk sex rated their own risk as high,justifyingthis by referring to their relatively low number of sex partners or to precautions which are ineffective, such as inspecting their partners for lesionsor showering after sex [4].

Positive associations between optimism and health has been shown [5]. This is particularly true regarding cardiovascular disease [6], stroke [7], depression [8] and cancer [9]. Optimism is alsopositively related to psychological well-being, optimists facing problems head-on, taking active and constructive steps to solve their problems, while pessimists are more likely to abandon their effort to attain their goals [10].

In Cognitive-Behavioral Therapy (CBT) pessimism is unequivocally defined as one of three dimensions of depression. Beck's [11] cognitive triangle involves negative thoughts about the self (i.e., the self is worthless), the world/environment (i.e., the world is unfair), and the future (i.e., the future is hopeless). Thinking pessimistically about the future, depressed individuals believe that their troubles will continue indefinitely and that the future will only bring further hardship, deprivation, and frustration.

In contrast, studies suggested that depressed people are likely to have inflated self-images and look at the world through "rose-colored glasses", thanks to cognitive dissonance elimination and a variety of other defense mechanisms that allow them to ignore or otherwise look beyond the harsh realities of life $[12,13]$.

Central to the study of pessimism vs. optimism is the term "Defensive Pessimism", a cognitive strategy used by individuals to prepare for anxiety provoking events or performances. Defensive pessimists set low expectations for their performance, regardless of how well they have done in the past [14]. Using this strategy, they can harness their anxiety, which might otherwise harm their performance, in an adaptive manner [15]. Unlike pessimism in general, defensive pessimism is not an internal, global, and stable attribution style, but rather a cognitive strategy utilized within the context of certain goals [14]. Though defensive pessimists are less satisfied with their performances, they do not actually perform worse than people with a more optimistic strategy do. A cognitive strategy to which the strategy of defensive pessimism is frequently compared is strategic optimism. Facing certain situations, strategic optimists feel that it will end well; hence, they make preparations but do not plan any more than they absolutely think they need to, because they do not have any anxiety to face.

Since the successful introduction of protease inhibitors as primary HIV treatmentwas reported in 1996 [16-18], researchers have speculated that being diagnosed with HIV might be perceived as less serious, as treatment mitigating the impact of the virus became available. This view is known as HIV Treatment Optimism (HTO) [19]. Several studies indicate that optimistic beliefs about HIV treatments are associated with increased sexual risk taking among MSM [19]. Heijman

Correspondence to: Rubinstein G, School of Behavioral Sciences, Netanya Academic College, Netanya, Israel; E-mail: gidirubi@netvision.net.il

Key words: HIV, AIDS, treatment optimism, personality, risk taking

Received: September 27, 2015; Accepted: October 21, 2015; Published: October 24,2015 
et al. [20] report that recently seroconverted MSM reduce their sexual risk behavior following HIV diagnosis, but this reduction becomes smaller in the HAART period and returns to pre-HAART levels within four years. Prestage et al. [21] identified two HTO measures, Health Optimism and Transmission Optimism, and concluded that HTO remains a useful indicator of gay men's likelihood to take risks, with their beliefs about HIV transmission risk reflecting willingness to pursue pleasure stronger than fear of risk.

The hypotheses of this study predict that HTO would be positively related to Acceptance of Sexual Orientation, E, ImpSS, and Frequency of Unprotected Anal Sex and negatively related to C, N, Condom Use Assertiveness, and Education (which involves long-term planning). This prediction is based on XXXX this ended abruptly!! Also, why do you use so many capital letters? This paragraph in particular, but also elsewhere.

\section{Method}

\section{Participants}

The participants were $301 \mathrm{MSN}$ (mean age=33.97, $\mathrm{SD}=10.86$ ), recruited from Atrafdating, the most popular gay dating website in Israel. Many gay men, who have already found a relationship, stay connected to this site for social chat or ex-relationship sex. They may therefore be considered a sample representative of a large section of Israeli MSM. All the participants were Jewish. 30.9\% of them defined themselves atheists, $54.9 \%$ secular, $12.2 \%$ traditional, and $2.1 \%$ religious. $38.9 \%$ of them were of Ashkenazi origin, $30.9 \%$ were of Sephardic origin, and $25.6 \%$ were mixed. 32\% graduated high school, $40 \%$ were undergraduate students and B.A. or B.Sc. holders, $22 \%$ were graduate or Ph.D. students and M.A. or Ph.D. holders. $81 \%$ were single, $4 \%$ were married to women, $10.6 \%$ were married to or living with men. $60.1 \%$ were completely out of the closet, $16.6 \%$ were partially in the closet, and $16.9 \%$ were completely in the closet. $49.7 \%$ defined themselves as sexually "versatile", $26.4 \%$ as exclusively "bottoms", $20.2 \%$ as exclusively "tops", and 3.8\% as avoiding any anal penetration. $9 \%$ were HIV patients under HAART and $88 \%$ were nonpatients. (In cases of missing values, percentages do not add up to $100 \%)$.

\section{Measures}

Demographic Questionnaire, which included items on age, relationship status education, occupation, ethnic origin, and religiosity.

NEO-FFI [22]. An authorized shortened Hebrew translation of the NEO-FFI was used in the present study. It consists of 60 items, 12 for each factor. For each item, participants express agreement or disagreement on a five-point Likert type scale ranging from "completely disagree" (1) to "fully agree" (5). Half of the items in each sub-scale are worded positively and half are worded as to avoid response set bias. The items of the different factors are mixed, every fifth item represents different factor. Cronbach's [23] alphas in the present study are 0.78 for Neuroticism $(\mathrm{N}), 0.77$ for Extraversion (E), 0.70 for Agreeableness (A), 0.82 for Conscientiousness (C), and 0.68 for Openness to Experience $(\mathrm{O})$.

ImpSS. The 19-item Impulsive Sensation Seeking (ImpSS) is part of the larger Zuckerman-Kuhlman Personality Questionnaire and is comprised of eight items gauging impulsivity and 11 items measuring sensation seeking [24]. Possible responds are either "right" or "wrong”. In this study, the two separate factors have not reached satisfactory internal consistency, but Cronbach's alpha for the scale as a whole was 0.94.
Heterosexual-Homosexual Rating Scale. A single item asking participants to define their sexual orientation on a 7-point Likert scale ranging from "Exclusively heterosexual with no homosexual" (0) to Exclusively homosexual (6) [25].

Acceptance of Sexual Orientation, which constituted of thequestion "If you could change your sexual orientation from homosexual to heterosexual by pressing a button at this stage of your life, would you do that?", possible responses ranging from "Certainly yes" (1) to "Certainly no" (4).

Condom Use Assertiveness (CUA) [26]. A four-item measuring sexual insistence on condom use, possible responses ranging from "never" (1) to "repeatedly" (5). Cronbach's s alpha for this scale in this study is 0.73 .

Condom Fatigue Scale (CFS). Eight items (e.g., pressure of the sexual partner, erroneous perception of risk, condom related erectile dysfunction) were developed based on Shidlo et al. [27] Unprotected Anal Intercourse Attitudes Inventory, possible responses ranging from "Absolutely wrong" (1) to "Absolutely right" (5) and Cronbach's alpha being 0.73 .

HIV Related Items. Several single items asking participants to report about their sexual preferences (anally penetrated, penetrating, or versatile), frequency of anal unprotected sex, HIV tests, HIV carrying, drug and/or alcohol use during sex, etc.

HIV Treatment Optimism Scale (HOT). HTO was assessed by a newly created 15-items measure, based on attitudes of HIV specialists andMSM laymentoward living with HIV in the HAART era (see Procedure). The attitudes of the laymen were considered "optimistic" items (e.g., "Having sex with a HIV carrier who regularly takes his medication is quite safe"), whereas those of the HIV specialists were considered "anti-optimistic" (e.g., items HIV may cause other medical problems), which had to be reversed. A 5-point Likert scale was used, ranging from "Strongly disagree" (1) to "Strongly disagree" (5). Cronbach's alpha for the HOT as a whole was 0.81 .

\section{Procedure}

The study was conducted in two stages. In the first one, heads of AIDS clinics in medical centers and general practitioners in an LGBT medical center, as well as gay laymen, were asked to describe living with HIV medically, socially, and emotionally. Four physicians and 16 gay laymen messaged their responses. The laymen were chosen from AtrafDating, the central Israeli gay dating website. Based on the responses a 18-item scale was created, out of which three items were excluded from the final version to achieve satisfactory internal consistency.

In the second stage the full questionnaire was uploaded to Google Docs and messages that included an APA ethics statement, were sent to all online members of the website, explaining the importance of identifying risk factor of HIV. A special version was considerately worded for HIV patients, who were identified by their nicknames (e.g., "a positive guy"). Links to both smartphone and computer versions were included in every message. During April-June 2013, the messages were sent in shifts $24 / 7$ as to give similar chances to married men, clubbers, casual sex seekers, and relationship seekers to be included in the sample. 


\section{Results}

\section{Factor analysis of the HTO}

Since the HTO is a newly created measure, its psychometric properties are presented in some details before the results of the hypothesis testing is presented.

An exploratory factor analysis (PCA) was carried out to determine how many interpretable factors explained thevariance in the HTO items. Four factorswere retained based on an examination of Catell's [28] scree test, Kaiser's eigenvalue rule [29], and comprehensibility. Thelowest eigenvalue of the five factors retained was 1.91. Varimax with Kaiser normalization was used to rotate the factors to yield an interpretablesolution. After rotation, the lowest eigenvalue was 3.43. Table 1 lists the item loadings for each factor, with the percentage of the varianceof each factor.

As can be seen, the scale as a whole explains $49.52 \%$ of the variance and its internal consistency is satisfactory $(\alpha=0.81)$.The first factor alone explains $15.03 \%$ of the variance and although it includes only four items, its internal consistency is relatively high $(\alpha=0.78)$. All these four items refer to medical complications, which were specified by the HIV specialists and therefore had to be revised as to express treatment optimism.

Cronbach's alphas of the other three factors are all below 0.70 , hence doubts may be raised regarding their use of sub-scales. The second factor alone explains $12.85 \%$ of the variance and its internal consistency $(\alpha=0.68)$ is almost acceptable [30]. All its five items were specified only by the HIV specialists as psychosocial problems involved in living with HIV and therefore had to be revised as to measure treatment optimism.

Crobabach's alphas of the remaining two factors fall within the range of $0.50-0.60$, which in itself is considered to be "poor" [30]. However, each factor includes only three items and a greater number of items might artificially inflate the value of alpha [31]. Moreover,
Cronbach [23] himself argues that if a scale is created via factor analysis an alpha above 0.50 should be considered acceptable. It was therefore decided to refer to the two remaining factors as sub-scales of the HTO, although they should be treated with caution because of the small number of items [32]. These two factors are both based MSM's attitudes regarding living with HIV and express optimistic biases [1]. The third factor explains $10.82 \%$ of the variance, its alpha is 0.57 , and it consists of three items, referring to the chronicity aspect of living with HIV. The forth factor explains $10.80 \%$ of the variance, its alpha is also 0.57 , and it contains three items, referring to the sexual risk taking aspect of living with HIV and are clearly supportive of unprotected anal intercourse, given the HAART.

\section{Hypothesis testing}

To assess the construct validity of the HTO, several five multiple regression analyses of the associations between the HTO subscales and the scale as a whole and conceptually related variables were conducted. The results of these analyses are presented in Table 2.

As can be seen, the medical factor is positively related to HIV, Acceptance of Sexual Orientation and Frequency of Unprotected Anal Sex and negatively related to Education and having periodical HIV tests. The psychosocial factor is positively related to Acceptance of Sexual Orientation, Using Alcohol and Drugs during Sex, and Frequency of Unprotected Anal Sex. Two personality traits are included in the regression equation of this factor, both $\mathrm{N}$ and $\mathrm{C}$ being negatively related the psychosocial factor. Baring in mind the caution with which the results regarding the chronicity and the risk taking factors have to be refereed to, the chronicity factor is positively related to age, HIV carrying, E, and condom fatigue and negatively related to C, Education, and being in the closet. The sexual risk taking factor is positively related to Age and Condom Fatigue and negatively related to Condom Use Assertiveness and Education. Finally, the total HTO is positively related to Age, HIV Carrying, Acceptance of Sexual Orientation, and Frequency of Unprotected Anal Intercourse and negatively related to Condom Use Assertiveness, Education, and C.

Table 1. Factor Loadings and Cronbach Alpha Coefficients for Exploratory Factor Model of the HTO.

\begin{tabular}{|c|c|c|c|}
\hline & $\begin{array}{l}\text { Factor } \\
\text { Loading }\end{array}$ & $\begin{array}{c}\text { Percentage of } \\
\text { Variance }\end{array}$ & $\alpha$ \\
\hline $\begin{array}{l}\text { Factor 1: Medical } \\
\text { Life with HIV is not easy at all and requires medical follow-up and many vaccinations (R) } \\
\text { HIV medications have side effects (R) } \\
\text { HIV may cause other medical problems (R) } \\
\text { HIV carrying may cause earlier and faster aging }(\mathrm{R})\end{array}$ & $\begin{array}{l}.69 \\
.81 \\
.79 \\
.60\end{array}$ & $15.03 \%$ & .78 \\
\hline $\begin{array}{l}\text { Factor 2:Psychosocial } \\
\text { HIV carrying might involve entering a "new closet" (R) } \\
\text { The problems HIV carriers face may result in depression (R) } \\
\text { The problems HIV carriers face negatively affect their social functioning (R) } \\
\text { HIV carrying may cause problems in having children (R) } \\
\text { HIV carrying may hinder immigration and force the carrier which to stay in Israel (R) }\end{array}$ & $\begin{array}{l}.59 \\
.68 \\
.70 \\
.50 \\
.56\end{array}$ & $12.85 \%$ & .68 \\
\hline $\begin{array}{l}\text { Factor 3: Chronicity } \\
\text { In the worst case, HIV carrying means living with a chronic disease like high blood pressure or juvenile diabetes } \\
\text { One can live peaceful and healthy life thanks to the newmedications } \\
\text { Having sex with a HIV carrier who regularly takes his medication is quite safe }\end{array}$ & $\begin{array}{l}.69 \\
.81 \\
.79\end{array}$ & $10.82 \%$ & .57 \\
\hline $\begin{array}{l}\text { Factor 4: Risk Taking } \\
\text { One can forgo condom use even in casual anal intercourse The new medications make periodical HIV test } \\
\text { unnecessary The new medications may be considered a "Breakfast of Champions" which makes unprotected anal } \\
\text { sex possible }\end{array}$ & $\begin{array}{l}.69 \\
.81 \\
.79\end{array}$ & $10.80 \%$ & .57 \\
\hline Total: HIV Treatment Optimism & & $49.52 \%$ & .81 \\
\hline
\end{tabular}


Table 2. Summary of Multiple Regression Analysis for Variables Predicting HTO.

\begin{tabular}{|c|c|c|c|c|c|}
\hline Factor & Variable & $r$ & B & SE B & $\boldsymbol{\beta}$ \\
\hline \multirow{5}{*}{ Medical } & HIV Carrying & $-.38^{* * *}$ & -.94 & .14 & $-.37 * * *$ \\
\hline & Acceptance of Sexual Orientation & $-.12 *$ & -.09 & .03 & $-.14 *$ \\
\hline & Education & $-.16 * *$ & -.06 & .02 & $-.16^{* *}$ \\
\hline & Having HIV Tests & .09 & .04 & .02 & $.11 *$ \\
\hline & Frequency of Unprotected Anal Intercourses & $-.20 * * *$ & -.18 & .08 & $-.13 *$ \\
\hline R2 & & \multicolumn{4}{|c|}{$.22 * * *$} \\
\hline \multirow{5}{*}{ Psychosocial } & Acceptance of Sexual Orientation & $-.26^{* * *}$ & -.14 & .03 & $-.23 * * *$ \\
\hline & Frequency of Unprotected Anal Intercourses & .11 & .06 & .03 & $.12 *$ \\
\hline & Neuroticism & $-.18^{* *}$ & -.19 & .06 & $-.20 * * *$ \\
\hline & Conscientiousness & $-.12 *$ & -.20 & .06 & $-.19 * * *$ \\
\hline & Use of Alcohol and Drugs during Sex & -.08 & -.08 & .04 & $-.12 *$ \\
\hline R2 & & \multicolumn{4}{|c|}{$.15^{* * *}$} \\
\hline \multirow{8}{*}{ Chronicity } & Education & -.03 & -.04 & .02 & -.09 \\
\hline & Age & $.24 * * *$ & .02 & .00 & $.25 * * *$ \\
\hline & HIV Carrier & $-.22 * * *$ & -.55 & .15 & $-.22 * * *$ \\
\hline & Ethnicity & $-.19 * *$ & -.22 & .09 & $-.14 *$ \\
\hline & Extraversion & .06 & .19 & .08 & $.15^{*}$ \\
\hline & Being in the Closet & $.21 * * *$ & .31 & .13 & $.15^{*}$ \\
\hline & Reasons for Condom Fatigue & -.07 & -.14 & .07 & $-.12 *$ \\
\hline & Conscientiousness & -.10 & -.21 & .08 & $-.17 * *$ \\
\hline R2 & & \multicolumn{4}{|c|}{$.22 * * *$} \\
\hline \multirow{4}{*}{ Risk Taking } & Condom Assertiveness & $-.63 * * *$ & -.42 & .03 & $-.59 * * *$ \\
\hline & Age & $.21^{* * *}$ & .01 & .00 & $.16^{* * *}$ \\
\hline & Education & -.03 & -.03 & .02 & $-.10^{*}$ \\
\hline & Reasons for Condom Fatigue & $.26 * * *$ & .11 & .04 & $.12 *$ \\
\hline R2 & & \multicolumn{4}{|c|}{$.44 * * *$} \\
\hline \multirow{7}{*}{ Treatment Optimism } & Education & $-.13 *$ & -.05 & .01 & $-.19 * * *$ \\
\hline & Condom Assertiveness & $-.35^{* * *}$ & -.15 & .03 & $-.26 * * *$ \\
\hline & HIV Carrying & $-.32 * * *$ & -.35 & .10 & $-.19 * * *$ \\
\hline & Age & $.16^{* *}$ & .01 & .00 & $.19^{* * *}$ \\
\hline & Acceptance of Sexual Orientation & $-.18 * *$ & -.08 & .03 & $-.18 * * *$ \\
\hline & Frequency of Unprotected Anal Intercourses & $.16^{* *}$ & .06 & .02 & $.14^{* * *}$ \\
\hline & Conscientiousness & -.10 & -.08 & .04 & $-.10 *$ \\
\hline R2 & & \multicolumn{4}{|c|}{$29 * * *$} \\
\hline
\end{tabular}

Note. ${ }^{*} p<.05, * * p<.01, * * * p<.001$.

These results fully support the hypothesis with respect to C, HIV Carrying, Acceptance of Sexual Orientation, Frequency of Unprotected Anal Intercourse, Condom Use Assertiveness, Education, and partially support the hypothesis with respect to E and N. In contrast, the ImpSS has not been included in any of the regression equations.

\section{Discussion}

In his classic novella Candide: Or, Optimism Voltair [33] argues that optimism is the madness of insisting that all is well when we are miserable. The combination of the benefits of optimism to health and coping with diseases together with the risks inherent to optimistic bias suggests that optimism might be a two-edged weapon. Out of the adjective list of the dating site itself, all the HIV patients in the dating website (rather than just those who participated in this study) had chosen the "optimistic" as the only trait characterizing themselves.

The results of this studysuggest that the HTO has preliminary promise as an assessment tool in prevention and education settings with HIV-negative or untested MSM. The four HTO factors express both attitudes of HIV specialists and MSM: (1) Medical complications of living with treated HIV, (2) Psychosocial aspects of HIV carrying, (3) Idealization of the Chronicity aspect of living with HIV, and (4) Sexual Risk Taking as a result of unrealistic optimistic bias related to HAART. The associations found between the HTO and C, HIV Carrying, Acceptance of Sexual Orientation, Frequency of Unprotected Anal Intercourse, Condom Use Assertiveness, Education, and partially with respect to E and N support the construct validity of the HTO on both behavioral and personality levels.

Another finding, which may have preventive and health educational implications, is the negative effects of education on each one of the factors and one the HTO as a whole. Moreover, as is the case with "optimistic" as the exclusive adjective used by HIV patients to define themselves, all of them (rather than just those who participated in the study) completed only high school, whereas the vast majority of non-patients were either undergraduate students or academic degree holders. This leaves room for hope that increased medical education and preventive efforts to emphasize the medical complications and the psychosocial consequences of living with HIV in the HAART era (rather than just emphasizing that HIV is no more a terminal but just 
a chronic disease) would combat condom burnout and increased HIV rates. This recommendation is also indirectly supported by the fact that persons of low literacy were more likely to miss treatment doses because of confusion, depression, and desire to cleanse their body than were people with higher health literacy $[34,35]$. On a theoretical-conceptual level, it is suggested to consider HTO, particularly the Chronicity and the Sexual Risk Taking factors based on too optimistic attitudes of MSM, as a case of optimistic bias regarding personal risks [1].

Finally, some limitations of this study should be referred to. First, the HTO presented here was developed in Hebrew and administered among Jewish Israeli MSM. The external validity of the results are therefore culturally limited. An English version of the scale and its investigation in other cultures are welcome. Secondly, although members of gay dating websites represent a large section of MSM, additional sampling methods are recommended. Third, because the sub-representation of HIV patients in this study, it is recommended that future HTO studies should include more such participants, preferably both patients who are and are not treated by the HAART, as HIV patients under HAART are expected to have better knowledge and opinions, which may effect their HTO level. It is also suggested that the effects of HTO on coping of HIV patients with its medical and psychosocial implications should be studied [36-39].

\section{References}

1. Weinstein ND (1989) Optimistic biases about personal risks. Science 246: 1232-1233. [Crossref]

2. Shepperd JA, Patrick C, Jodi G, Meredith T (2002) Exploring the causes of comparative optimism. Psychologica Belgica 42: 65-98.

3. Helweg-Larsen M, Shepperd JA (2001) Do moderators of the optimistic bias affect personal or target risk estimates? A review of the literature. Personality and Social Psychology Review 5: 74-95.

4. Bauman LJ, Siegel (1987) Misperception among gay men of the risk for AIDS associated with their sexual behavior. Journal of Applied Social Psychology 17: 329-350.

5. Peterson C, Park N, Kim ES (2012) Can optimism decrease risk of illness and disease among the elderly? Aging Health 8: 5-8.

6. Tindle HA, Chang YF, Kuller LH, Manson JE, Robinson JG, et al. (2009) Optimism, cynical hostility, and incident coronary heart disease and mortality in the Women's Health Initiative. Circulation 120: 656-662. [Crossref]

7. Kim ES, Park N, Peterson C (2011) Dispositional optimism protects older adults from stroke: the Health and Retirement Study. Stroke 42: 2855-2859. [Crossref]

8. Patton GC, Tollit MM, Romaniuk H, Spence SH, Sheffield J, et al. (2011) A prospective study of the effects of optimism on adolescent health risks. Pediatrics 127: 308-316. [Crossref]

9. Allison PJ, Guichard C, Fung K, Gilain L (2003) Dispositional optimism predicts survival status 1 year after diagnosis in head and neck cancer patients. J Clin Oncol 21: 543-548. [Crossref]

10. Scheier C, Carver M, Bridges M (2001) Optimism, pessimism, and psychological wellbeing. In: Chang EC (Ed.), Optimism and pessimism: Implications for theory, research, and practice (pp. 189-216). Washington, DC: American Psychological Association.

11. Beck AT (1976). Cognitive therapy and the emotional disorders. New York: Meridian.

12. Alloy LB, Abramson LY (1979) Judgment of contingency in depressed and nondepressed students: sadder but wiser? J Exp Psychol Gen 108: 441-485. [Crossref]

13. Dobson K, Franche RL (1989) A conceptual and empirical review of the depressive realism hypothesis. Canadian Journal of Behavioral Science 21: 419-433.

14. Norem JK (2001) Defensive pessimism, optimism, and pessimism. In: Chang EC (Ed.), Optimism and pessimism: Implications for theory, research, and practice (pp. 77-100). Washington, DC: American Psychological Association.

15. Norem JK, Cantor N (1986) Defensive pessimism: harnessing anxiety as motivation. $J$ Pers Soc Psychol 51: 1208-1217. [Crossref]

16. Cameron W, Heath-Chiozzi M, Kravcik S (1996) Prolongation of life and prevention of
AIDS in advanced HIV immunodeficiency with ritanovir. Paper presented at the Third Conference on Retroviruses and Opportunistic Infections, Washington, DC.

17. Deeks SG, Smith M, Holodniy M, Kahn JO (1997) HIV-1 protease inhibitors. A review for clinicians. JAMA 277: 145-153. [Crossref]

18. Hammer SM (1996) Advances in antiretroviral therapy and viral load monitoring. Paper presented at the 11th International AIDS Conference, Vancouver, British Columbia, Canada.

19. Brennan DJ, Welles SL, Miner MH, Ross MW, Rosser BR, et al. (2010) HIV treatmen optimism and unsafe anal intercourse among HIV-positive men who have sex with men: findings from the positive connections study. AIDS Educ Prev 22: 126-137. [Crossref]

20. Heijman T, Geskus RB, Davidovich U, Countinho RA, Prins M, et al. (2012) Less decrease in risk behavior from pre-HIV to post-HIV seroconversion among MSM in the combination antiretroviral therapy ear compared with the pre-combination antiretroviral therapy era. AIDS 26: 489-495. [Crossref]

21. Prestage G, Down IA, Bradley J, McCann PD, Brown G, et al. (2012) Is optimism enough? Gay men's beliefs about HIV and their perspectives on risk and pleasure. Sex Transm Dis 39: 167-172. [Crossref]

22. Costa PT, McCrae RR (1992) Revised NEO Personality Inventory (NEO PI-R) and NEO Five-Factor Inventory (NEO-FFI): Professional manual. Odessa, Florida: Psychological Assessment Resources.

23. Cronbach LJ (2004)My current thoughts on coefficient alpha and successor procedures Educational and Psychological Measurement 64: 391-418.

24. Zuckerman M (2002) Zuckerman-Kuhlman Personality Questinnaire (ZKPQ): An alternative five-factorial model. In: De Raad B, Peraigini M (Eds.), Big Five assessment (pp. 377-396). Seatle, WA: Hogrefe\& Huber.

25. Kinsey AC, Pomeroy W, Martin CE (1948) Sexual behavior in the human male Philadelphia and London: Saunders.

26. Grimley DM, Prochaska GE, Prochaska JO (1993) Condom use assertiveness and the stages of change with main and other partners. Journal of Applied Biobehavioral Research 1: 152-173.

27. Shidlo A, Yi H, Dalit B (2005) Attitudes toward unprotected anal intercourse: Assessing HIV-negative gay or bisexual men. Journal of Gay and Lesbian Psychotherapy 9: 107-128.

28. Catell RB (1966)Thescree test for the number of factors. Multivariate Behavioral Research 1: 140-161.

29. DeVellis RF (1991) Scale development: Theory and applications. Newbury Park,CA Sage.

30. Kline P (1999) The handbook of psychological testing (2ndedn), London: Routledge

31. Cortina JM (1993)What is coefficient alpha? An examination of theory and applications. Journal of Applied Psychology 78: 98-104.

32. Tabachnik BG, Fidell LS (1983) Using multivariate statistics. New York:Harper \& Row.

33. Voltaire FMA (1959) Candid: Or, optimism. New York: Bantam Dell.

34. Kalichman SC, Ramachandran B, Catz S (1999) Adherence to combination antiretroviral therapies in HIV patients of low health literacy. $J$ Gen Intern Med 14: 267-273.[Crossref]

35. Ronson B, Rootman I (2009) Literacy and health literacy: New understandings about their impact on health. In: Raphael P (Ed.), Social determinants of health (2ndedn), (pp. 170-187). Toronto, Ontario: Canadian Scholars' Press.

36. Sharpe J, Martin N, Roth K (2011) Optimism and the Big Five factors of personality: Beyond Neuroticism and Extraversion. Personality and Individual Differences 51: 946-951.

37. Sthoeger Z (Ed) (2013) HIV/AIDS [Special issue]. Harefuah: Journal of the Israel Medical Association.

38. World Health Organization (2012) WHO HIV drug resistance report. Geneva: Author.

39. Wright LW, Bonita AG, Mulick P (2011) Update and reflections on fear and discrimination against bisexuals, homosexuals, and individuals with AIDS. Journal of Bisexuality 11: 458-464.

Copyright: (C2015 Rubinstein G. This is an open-access article distributed under the terms of the Creative Commons Attribution License, which permits unrestricted use, distribution, and reproduction in any medium, provided the original author and source are credited. 